\section{The Influence of Learning Motivation on Student Achievement Studying Economics at Mahadika Ciracas Vocatioanl High School}

\author{
Pengaruh Motivasi Belajar dengan Prestasi Belajar Ekonomi Siswa di SMK Mahadika \\ Ciracas
}

Syarifah Nurul Mulki, S.Pd

Universitas Indraprasta PGRI

Jalan Raya Tengah No.80, RT.6/RW.1, Gedong, Kec. Ps. Rebo, Kota Jakarta Timur, Daerah

Khusus Ibukota Jakarta 13760

\begin{abstract}
This research aimed to know how big effect of learning motivation on student achievement studying economics at Mahadika Ciracas vocational high school. The research used a quantitative method with descriptive approach. Population in this research is all of accounting students $X$ grade 1 and 2 at SMK Mahadhika Ciracas with a total of 67 students. Because the sample is less than 100, the entire population is also used as a research sample. To test data analysis using method of Product Moment Correlation, Coefficient of Determination and Hypothesis test. Conlucions is there are no effect between the influence of learning motivation on student achievement studying economics at mahadika ciracas vocational high school. It can be the results of $t_{-}$count $=0.533$ with $t_{-}$table $=1,670$ at the level of $5 \%=$ and $d k=N-2=67-2=65$, so the value of $t$-count $\leq$ table. Which means that Ha was rejected and Ho was accepted.
\end{abstract}

Keywords: learning motivation, student achievement

\title{
PENDAHULUAN
}

Lemahnya motivasi untuk belajar dalam diri siswa itu sendiri, merupakan faktor utama yang dialami oleh kebanyakan siswa saat ini. Tak terkecuali di SMK MahadhikaCiracas, motivasi yang melemah saat ini di SMK tersebut bukan hanya disebabkan oleh tenaga pengajarnya yang kurang matang dalam membawakan materi, dan membuat berbagai metode pengajaran yang demikian menarik, sehingga murid senang, dan memiliki rasa ingin tahu yang tinggi guna mendapatkan prestasi yang maksimal, namun peran orang tua disini juga sangat penting, dalam memberikan motivasi kepada sang anak tentang pentingnya suatu pendidikan dan prestasi belajar dalam membangun bangsa yang kuat.

Bukan hanya itu kemajuan teknologi juga sangat berperan aktif dalam menurunkan motivasi berprestasi siswa di SMK Mahadika, karena di SMK tersebut sudah menggunakan kecanggihan teknologi dalam proses belajar mengajar, memang kita sebagai manusia harus mampu mengikuti perubahan zaman dengan mengetahui dan memanfaatkan kecanggihan teknologi ini, namun sisi buruknya kecanggihan teknologi membuat siswa malas dalam membaca buku dan merangkum, mereka lebih senang searching di internet dan mengcopynya ke dalam sebuah persentase yang akan ditayangkan di dalam setiap kali pertemuan kelas, yang mereka sendiripun tidak mengetahui maksud dari materi tersebut.

Padahal, pelajaran Ekonomi sendiri merupakan pelajaran inti di SMK Mahadika, bagi yang mengambil jurusan ekonomi. Ekonomi merupakan tombak dalam pembangunan suatu bangsa, wajar saja jika penulis mengatakan bahwa jika suatu negara ingin maju, maka 
Literatus is a journal published by PT Traindo Bangun Negeri, issued two times in one year. Literatus is a scientific publication media in the form of conceptual paper and field research related to general thinking paradigm. It is hoped that Literatus can become a media for academics and researchers to publish their scientific work and become a reference source for the development of science and knowledge.

Our focus:

Social and Culture

Our Scope:

Humanities,

Education,

Management,

History,

Economics,

Linguistics,

Literature,

Religion,

Politics,

Sociology,

Anthropology,

and others.

hadirkan generasi yang mengerti akan ilmu ekonomi guna membangun negaranya. SMK adalah sekolah sadar akan tujuan untuk menghadirkan lulusan yang siap pakai di dunia kerja. Jika lemahnya motivasi terus meningkat dalam setiap mata pelajaran, terutama di pelajaran ekonomi, yang merupakan mata pelajaran inti bagaimana kelak generasi mendatang.

Berdasarkan paparan diatas maka peneliti tertarik untuk melakukan penelitian dengan judul Pengaruh Motivasi dalam Peningkatan Prestasi Siswa di SMK Mahadika Ciracas. Penelitian ini bertujuan untuk mengetahui seberapa besar Pengaruh Motivasi dalam Peningkatan Prestasi Siswa di SMK Mahadika Ciracas.

\section{Belajar}

Belajar ialah suatu proses yang dilakukan seseorang untuk memperoleh suatu perubahan tingkah laku yang baru secara keseluruhan, yang dijadikan sebagai hasil pengamatannya sendiri dalam interaksi dengan lingkungan (Slameto, 2013: 2). Menurut Surya (dalam Rusman, 2017: 76) belajar dapat diartikan sebagai suatu proses yang di lakukan oleh individu untuk memperoleh perubahan perilaku baru secara keseluruhan, sebagai hasil dari pengalaman individu itu sendiri dalam berinteraksi dengan lingkungannya.

\section{Prestasi Belajar}

Menurut Indrawati (2013:217) Prestasi belajar sebagai pebilaian pada hasil belajar yang diperoleh oleh siswa yang dinyatakan dalam bentuk symbol, angka, maupun kalimat pada periode tertentu atau dinyatakan dalam bentuk nilai raport. Hal ini menjadi fokus penelitian ini oleh karena relevan dengan konteks nilai raport yang akan digunakan dalam mengukur prestasi belajar siswa. Dapat di simpulkan bahwa prestasi merupakan sebuah hasil atau pencapaian atas berbagai usaha yang telah di lakukan setelah memperoleh pengalaman atau pelajaran.

\section{Motivasi Belajar}

Menurut Slameto (2013: 2) belajar ialah suatu proses yang di lakukan seseorang untuk memperoleh suatu perubahan tingkah laku yang baru secara keseluruhan, Yang dijadikan sebagai hasil pengamatannya sendiri dalam interaksi dengan lingkungan. Dari definisi diatas dapat disimpulkan bahwa Motivasi belajar adalah dorongan yang timbul pada diri seseorang secara sadar atau tidak sadar yang mengakibatkan orang tersebut rela guna mengerahkan kemampuan, tenaga, dan waktunya.

\section{METODE}

Metode penelitian yang digunakan dalam penelitian ini adalah metode kuantitatif dengan pendekatan deskriptif yaitu mengadakan observasi, expose data, dan penyebaran angket. Dengan data penelitian, di mana variable $\mathrm{X}$ adalah Pengaruh Motivasi Belajar, sedangkan Variabel Y adalah Prestasi Belajar Ekonomi siswa Kelas X Akuntansi di SMK Mahadika Ciracas. Populasi dalam penelitian ini adalah seluruh siswa kelas X Akuntansi 1 dan 2 di SMK Mahadika Ciracas dan jumlah sampel yang diteliti sebanyak 67 siswa. Teknik pengumpulan data dengan melakukan observasi serta dokumentasi. Instrumen penelitian yang digunakan dalam penelitian ini yaitu dengan menyebarkan kuisioner (angket). Teknik analisis data pada penelitian ini dengan menggunakan analisis regresi linier sederhana, analisis koefisien korelasi sederhana, koefisien determinasi serta melakukan pengujian hipotesis.

\section{HASIL DAN PEMBAHASAN}

\section{Hasil}

Berdasarkan hasil analisis regresi linier sederhana dengan persamaan regresi sederhana Diperoleh nilai $a$ sebesar 58,471 dan nilai $b$ sebesar 0,0813. Maka terbentuklah 
persamaan regresi linear sederhana $\mathrm{Y}$ atas $\mathrm{X}$ adalah

$$
\mathrm{Y}=58,471+0,0813 \mathrm{X}
$$

Dari persamaan regresi linear sederhana diatas didapat (b) bernilai positif, yakni + 0,0813X yang berarti bahwa terdapat hubungan keterkaitan antara variabel X (Motivasi) terhadap variabel Y (Prestasi Belajar). Bila Variabel X adalah 1 maka rata-rata Variabel Y (Prestasi Belajar) bertambah 0,073X. Sedangkan berdasarkan perhitungan analisis koefisien korelasi sederhana didapatkan hasil sebesar 0,064. Artinya besarnya hubungan antara kedua variabel $X$ (Motivasi belajar) terhadap variabel $Y$ (Prestasi belajar) sebesar 0,064 yang dimana dalam pedoman tabel interprestasikoefisen korelasi berada pada interval 0,00-0,199 yang berarti diantara kedua variabel memilki pengaruh yang sangat rendah.

Dari analisis koefisien determinasi didapatkan hasil sebesar 0,4096\%. Dapat disimpulkan besarnya pengaruh motivasi terhadap prestasi belajar siswa di SMK Mahadhika 1 ciracas adalah $0,4096 \%$ dan sisanya 99,5904\% lainnya dipengaruhi oleh faktor (variabel) lainnya. Pengujian hipotesis menggunakan uji $\mathrm{T}$ diperoleh $t_{\text {hitung }}=0,533$ dengan $t_{\text {tabel }}=1,670$ dengan taraf $5 \%=$ dan $\mathrm{dk}=\mathrm{N}-2=67-2=65$, sehingga dapat ditarik kesimpulan tidak terdapat pengaruh diantara kedua variabel yang artinya thitung $\leq$ ttabel, maka Ha ditolak dan $\mathrm{H} 0$ diterima artinya tidak ada pengaruh signifikan antara variabel $\mathrm{X}$ dan variabel $\mathrm{Y}$, yang menyatakan tidak adanya pengaruh motivasi dalam peningkatan prestasi belajar ekonomi siswa kelas X akuntansi di SMK Mahadhika 1 Ciracas.

\section{Pembahasan}

Berdasarkan pengujian hasil hipotesis yang telah diuraikan diatas yaitu uji korelasi diperoleh nilai persamaan regresi $\mathrm{Y}=58,471+0,0813 \mathrm{X}$, persamaan ini memberikan informasi bahwa setiap terjadi perubahan satu tingkat pada motivasi belajar tentu akan mengakibatkan terjadinya perubahan pada prestasi belajar siswa sebesar 58,471 dan konstanta $0,0813 \mathrm{X}$.

Hasil perhitungan korelasi menyimpulkan bahwa tidak terdapat hubungan positif antara motivasi belajar dalam peningkatan prestasi belajar mata pelajaran ekonomi kelas $\mathrm{X}$ akuntansi di SMK Mahadika 1 Ciracas, yang ditunjukan dengan nilai koefisien korelasi sebesar 0,064. Angka korelasi ini memberikan pengertian bahwa, keterkaitan antara motivasi belajar terhadap prestasi belajar mata pelajaran ekonomi tergolong sangat rendah. Hal ini sejalan dengan temuan penelitian yang pernah dilakukan sebelumnya (Inayah, Martono, \& Sawiji, 2013).

Berdasarkan perhitungan determinasi (KD) hasil yang diperoleh adalah sebesar $0,4096 \%$. Besar angka perhitungan determinasi ini memberikan pengertian bahwa prestasi belajar siswa akan meningkat jika motivasi belajar terus ditingkatkan, sedangkan sisanya sebesar 99,5904\% lainnya dipengaruhi oleh faktor (variabel) lain. Dengan ini penelitian Sunadi (2013) juga mendukung temuan ini yang menunjukkan bahwa ada pengaruh secara parsial antara motivasi belajar terhadap prestasi belajar.

Hasil analisis signifikan koefisien korelasi dilakukan menggunakan analisis uji t, yaitu diperoleh $t_{\text {hitung }}=0,533$ dengan $t_{\text {tabel }}=1,670$ pada taraf signifikan $5 \%(0,05)$. Yang menyatakan bahwa $t_{\text {hitung }} \leq t_{\text {tabel }}$, sehingga dapat ditarik kesimpulan bahwa tidak adanya pengaruh yang positif dan signifikan antara motivasi belajar dalam peningkatan prestasi belajar siswa mata pelajaran ekonomi kelas X akuntansi di SMK Mahadhika 1 Ciracas.

\section{PENUTUP}

Berdasarkan hasil penelitian dan pembahasan maka peneliti mengungkapkan bahwa tidak terdapat pengaruha ntara motivasi belajar dalam Peningkatan prestasi belajar ekonomi siswa kelas $\mathrm{x}$ di SMK Mahadhika 1 Ciracas. Yang dimana dibuktikan dengan hasil $t_{\text {hitung }}=0,533$ dengan $t_{\text {tabel }}=1,670$ pada taraf $5 \%=$ dan $\mathrm{dk}=\mathrm{N}-2=67-2=65$, sehingga nilai thitung $\leq$ tabel. Yang artinya Ha ditolak dan H0 diterima. 
Literatus is a journal published by PT Traindo Bangun Negeri, issued two times in one year. Literatus is a scientific publication media in the form of conceptual paper and field research related to general thinking paradigm. It is hoped that Literatus can become a media for academics and researchers to publish their scientific work and become a reference source for the development of science and knowledge.

Our focus:

Social and Culture

\section{Our Scope:}

Humanities,

Education,

Management,

History,

Economics,

Linguistics,

Literature,

Religion,

Politics,

Sociology,

Anthropology,

and others. research and development thinking paradigm

Berdasarkan hasil yang didapatkan peneliti menyarankan agar pihak sekolah khususnya para guru mau memberikan motivasi lebih kepada para siswa. Hal ini agar siswa mau mengulang dan mempelajari Pelajaran Ekonomi dengan semangat dan penuh motivasi. Pemberian motivasi ini dapat dilakukan dengan cara memberikan reward atau pujian saat proses belajar mengajar.

\section{DAFTAR PUSTAKA}

Inayah, R., Martono, T., \& Sawiji, H. (2013). Pengaruh Kompetensi Guru, Motivasi Belajar Siswa, dan Fasilitas Belajar terhadap Prestasi Belajar Mata Pelajaran Ekonomi pada Siswa Kelas XI IPS SMA Negeri 1 Lasem Jawa Tengah Tahun Pelajaran 2011/2012. Jurnal Pendidikan Insan Mandiri, 1(1), 1-13. Retrieved from https://eprints.uns.ac.id/1961/1/18994276-1-SM.pdf

Sunadi, L. (2013). Pengaruh Motivasi Belajar dan Pemanfaatan Fasilitas Belajar terhadap Prestasi Belajar Siswa pada Mata Pelajaran Ekonomi Kelas XI IPS di SMA Muhammadiyah 2 Surabaya. Jurnal Pendidikan Ekonomi, 1-19. Retrieved from https://jurnalmahasiswa.unesa.ac.id/index.php/jupe/article/viewFile/3628/6224 